\title{
The technological aspect of soybean seed separation
}

\author{
Victor Khamuev ${ }^{1}$, Maksim Moskovskiy ${ }^{1, *}$, and Hoang Ngia Dat ${ }^{2}$ \\ ${ }^{1}$ Federal Scientific Agro-Engineering Center VIM, 1 Institutsky proezd, 5, Moscow, 109428, Russia \\ ${ }^{2}$ Hanoi University of Agriculture, Hanoi, Vietnam
}

\begin{abstract}
The results of a study on the purification of soybean seeds by the combined use of a gravity column with a zigzag channel formed by a cascade of installed combs and a pneumatic separation channel with a vertically ascending air flow and with narrowing partitions installed in it are presented.
\end{abstract}

\section{Introduction}

The main working body for soybean separation is the sieve, on which the separation of impurities is a simple, proven technology. Nevertheless, sieve machines have their own disadvantages. For example, cleaning material from small impurities leads to clogging of sieve holes, which in turn leads to a decrease in productivity, therefore, special cleaning devices are used, which complicates the design of the machines and increases their energy and metal consumption [1-5]. In addition, for high-performance machines with high dynamic loads, the construction of special foundations is required, which leads to the cost of complexes for post-harvest soybean processing.

The search for new methods for separating soybean seeds can create conditions for the development of a new type of cleaning technologies that eliminate the disadvantages of traditional machines, as well as achieve more profitable technical and economic indicators of grain cleaning equipment [6-10].

The research aim is justify the design parameters of a treatment plant for highly efficient separation of soybean seeds.

\section{Material and methods}

The researches were carried out on the prototype of cleaning soybean seeds installation developed at ${ }^{1}$ Federal Scientific Agro-Engineering Center VIM (Figure. 1.).

Installation works as follows. The source material I (soybean after harvesting) is loaded into the receiving funnel 1 , from which it flows by gravity into the gravity column 2 . Under the action of gravitational forces, the material inside the column moves up and down along the zigzag channel formed by a cascade of installed combs, as a result of which the bulk of the grains passes in the gaps between the fingers of the combs, and a large impurity III

\footnotetext{
* Corresponding author: maxmoskovsky74@yandex.ru
} 
(stones, pieces of land, unfinished soybean pods) immediately descends from the combs and is removed from the machine through the corresponding pipe. The bulk of the soybean then flows by gravity to the supporting grid 5 of the pneumatic separation channel 3 , where in sections 7, 8 and 9 with narrowing partitions 4 under the influence of vertically ascending air flows II created by fans 11, light impurities V are released. as well as halves of soybean VI and sorted soybean VII with the lowest specific gravity of seeds.

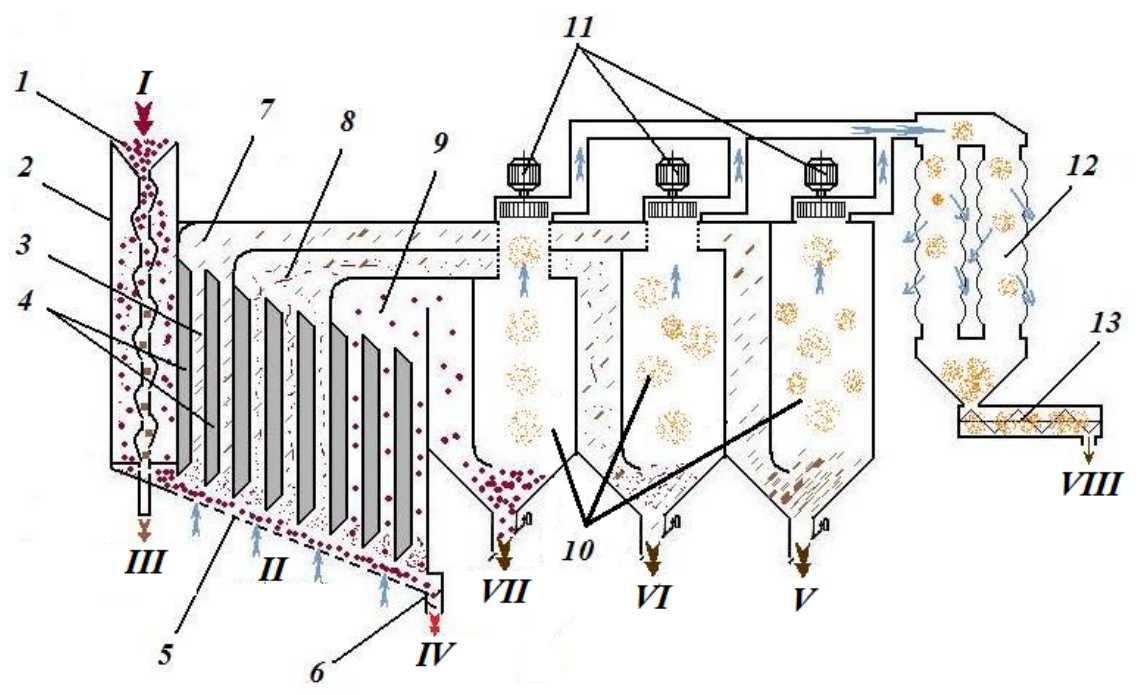

Fig. 1. The scheme of a prototype of installation for the separation of soybean seeds: 1 - receiving funnel; 2 - gravity column; 3 - pneumatic separation channel; 4 - narrowing partitions; 5 - supporting grid; 6 - outlet pipe; 7, 8 and 9 - 1, 2 and 3 sections of a pneumatic cleaning channel; 10 - sedimentary chambers; 11 - fans with electric motors; 12 - a dust collector; 13 - conveyor; I - source material; II air flow; III - large impurity; IV - peeled soybean seeds; V is a light impurity; VI - halves of soy; VII - sorted soybeans for forage; VIII - dust.

The cleaned material IV, moving along the supporting grid, is removed from the machines through the corresponding pipe 6.

The impurities emitted by the air streams are carried out into the sedimentation chambers 10 and discharged through the corresponding valves, which are closed by the vacuum formed in the chambers.

The air flow from the sedimentary chambers, passing through the fan, is cleaned of dust in the cloth filters of the dust collector 12. The separated dust VIII is collected in a special collection, from where it is discharged by the conveyor 13 .

It were substantiated in experiments:

1. The number of combs $\mathrm{N}$ in the gravitational column and the gap $\mathrm{C}$ between the bars of the combs.

2. The optimal ratio of the width $b$ of the narrowing partition and the depth $d=150 \mathrm{~mm}$ of the channel section $(b / d)$ while the specific grain load in the channel was $3 \mathrm{~kg} /\left(\mathrm{cm}^{2} \cdot \mathrm{h}\right)$, the width of the partitions: 0 (without partitions) 30, 60, 90 and $120 \mathrm{~mm}$, while the angle $\alpha$ of the bevel of the partition adopted 45 degrees.

After substantiating the main parameters of the narrowing partitions, studies were carried out to determine the completeness of $\varepsilon$ coarse impurities in the gravity column, light impurities in the I section of the channel, soy halves in the II section of the channel, small and puny soy seeds (not more than $4 \mathrm{~mm}$ ) in III sections of the channel with different supply of material for cleaning. 
The amount of soybean seeds taken into the waste in the research corresponded to the initial requirements (IR) for the main technological operations of post-harvest seed treatment [11].

We used a grain mixture with a moisture content of $11.9 \%$, consisting of soybean seeds with a purity of $96.11 \%$, coarse impurities (stones and ground pieces) - $0.68 \%$, light impurities (shell of beans) - 1.33\%, small and full soybean seeds (passage through a sieve Ø3 mm) - 0.71\%, broken soybean seeds (halves) - 1.17\%.

The experiments were carried out in triplicate, the relative error of the sample mean (accuracy of the experiments) was less than $5 \%$ with a confidence level of 0.9 .

\section{Results and discussion}

Graphs of the dependence of the separation efficiency $E$ of large impurities on the number of combs $\mathrm{N}$ at various gaps $\mathrm{C}$ between the bars of the combs are showed in the Figure. 2 . The graph shows that the optimal number of combs for the gravitational column is 10 pcs. with gaps between the bars of the combs $10 \mathrm{~mm}$, while the separation efficiency is $99.3 \%$, i.e. in this case, with $100 \%$ separation of large impurities, the loss of the main component is $0.7 \%$, which corresponds to IR [11].

The low cleaning efficiency $\left(E_{C=8 \mu u}=82.3 \%\right.$ at $N=14$ pcs. And $E_{C=12 \mu u}=77.9 \%$ at $\mathrm{N}$ $=8$ pcs.) is due to the fact that in the first case, the gaps between the bars of the combs are small, so some soybeans does not pass through the combs and gets into the waste together with the impurity (large losses of soybeans), and in the second case the gaps are large, therefore large impurities pass through the combs along with the main material (the completeness of the admixture decreases).

In Figure 3 shows graphs of the dependence of the completeness of the separation of impurities $\varepsilon$ on the ratio of the width of the narrowing septum $b$ and the depth of the section $\mathrm{d}$ of the pneumatic separation channel. The graphs show that the optimal b / d ratio with a maximum of curves for each impurity is approximately 0.37 , hence the width of the narrowing partitions will be $55.5 \mathrm{~mm}$.

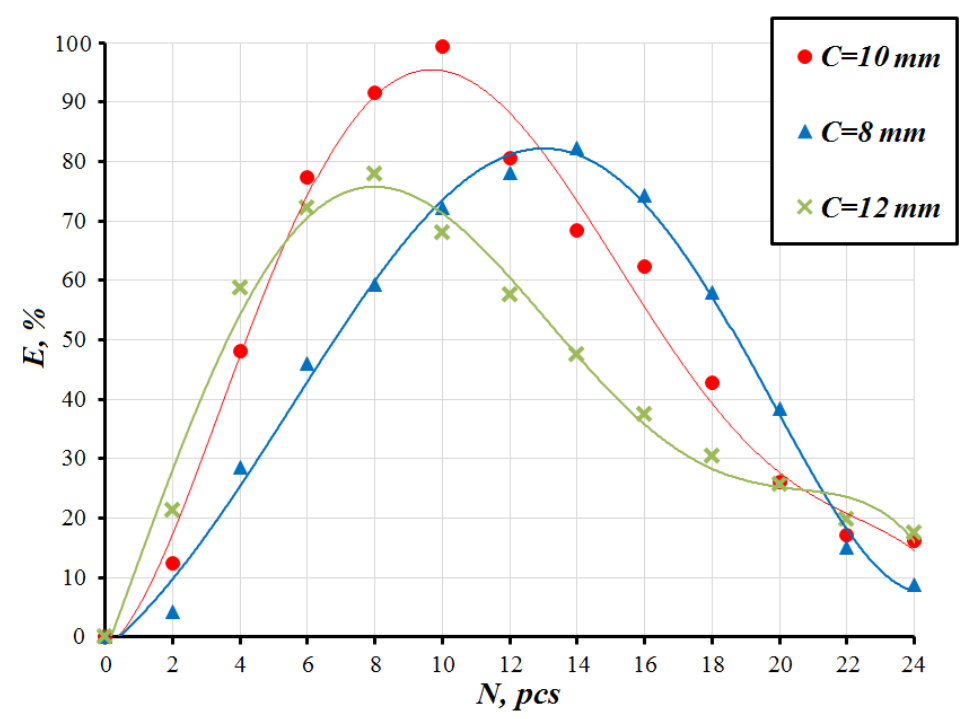

Fig. 2. The efficiency of the separation $E$ of a large impurity depending on the number of combs $N$ at various clearances $C$ between the bars of the combs. 


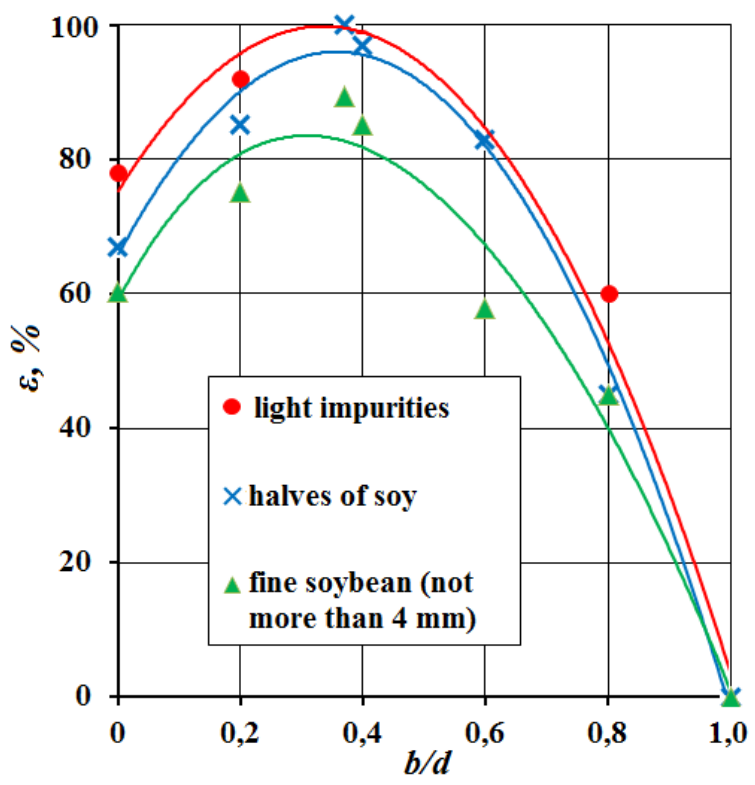

Fig. 3. Graphs of the dependence of the completeness of the separation of impurities $\varepsilon$ on the ratio of the width of the narrowing septum $b$ and the depth of the section $d$ of the pneumatic separation channel.

In Figure. 4 shows graphs of the dependence of the completeness of the separation of impurities $\varepsilon$ on the supply of material Q to the prototype of a treatment plant. The graphs show that the optimal supply of soybean is $2.5 \mathrm{t} / \mathrm{h}$, while the completeness of selection in the pneumatic channel is not lower than 98\%, and large impurities are not lower than 95\%.

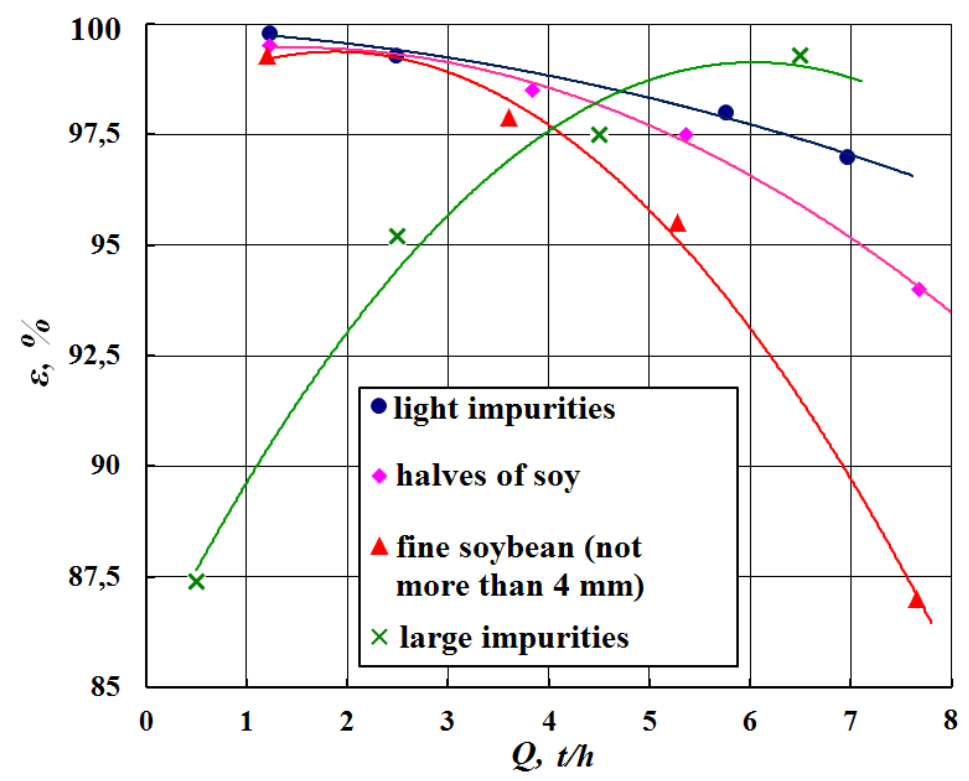

Fig. 4. Graphs of the dependence of the completeness of the separation of impurities $\varepsilon$ on the supply of material $\mathrm{Q}$ to the prototype of a cleaning installation 


\section{Conclusion}

It was shown that soybean cleaning is possible by the combined use of a gravitational column with a zigzag channel formed by a cascade of installed combs and a pneumatic separation channel with a vertically ascending air flow and narrowing partitions installed in it. It was found that the optimal number of combs for a gravity column is 10 pieces with gaps between the bars of the combs $10 \mathrm{~mm}$, while the separation efficiency is $99.3 \%$, that is, with $100 \%$ separation of large impurities, the loss of the main component is $0.7 \%$; the optimal supply of soybeans is $2.5 \mathrm{t} / \mathrm{h}$ (the completeness of release in the pneumatic channel is not lower than 98\%, and large impurities not lower than 95\%). This constructive solution makes it possible to increase the productivity and efficiency of soybean cleaning by at least $20 \%$, reduce material consumption by 2.3-4.8 times, energy intensity - by 4.2-6.1 times and the required volume of premises - by 4 , 2-6.1 times.

\section{References}

1. Fominykh A.V., Voinkov V.P., Fomina S.V. Soybean processing line using sieve and friction separators // Bulletin of Kurgan State Agricultural Academy. 2014. N4 (12). p. 66-69.

2. Shaforostov V.D., Priporov I.E. Technology for post-harvest processing of soybean seeds using domestic machines // Legumes and cereals. 2014. №4 (12). p. 119-122.

3. Ermolina O.V., Korotkova O.V., Lysenko A.A. Organization of primary soybean seed production // Grain Economy of Russia. 2015. №1. p. 34-39.

4. Shreekant P., Rameshwar K., Digvir J., Noel W. Mechanical Damage to Soybean Seed during Processing. Journal of Stored Products Research. 2002. N38. 385-394 (In English).

5. Barros F. C., Juliatti F. C. Levantamento de fungos em amostras recebidas no laboratório de micologia e proteção de plantas da Universidade Federal de Uberlândia, no período 2001-2008. Bioscience Journal. 2012. Vol. 28. 77-86 (In Portuguese).

6. Izmailov A.Yu., Lachuga Yu.F., Zyulin A.N. Development and implementation of highly effective, resource- and energy-saving technologies and technical equipment for post-harvest grain processing and seed preparation // Agricultural Machines and Technologies. 2009. Vol. 3. №1. 3. 2-8.

7. Smolyaninov Yu.N. Ways to improve the technology of post-harvest grain processing // Bulletin of science and practice. 2017. №11 (24). p. 97-102.

8. Gureeva E.V., Fomina T.A. Sources of economically valuable traits for soybean breeding in the Ryazan region // Bulletin of the Russian agricultural science. 2015. №6. p. 29-30.

9. Kroulík M., Hůla J., Rybka A., Honzík I. Pneumatic conveying characteristics of seeds in a vertical ascending airstream. Research in Agricultural Engineering. 2016. N62 5663.

10. Mechinsky V.E., Fominykh A.V., Voinkov V.P., Shestopalov I.S. The choice of the friction surface of the belt separator for cleaning soybeans // Bulletin of the Kurgan State Agricultural Academy. 2014. №1 (9). p. 56-57.

11. Elizarov V.P., Antyshev N.M., Beilis V.M., Shevtsov V.G. Initial requirements for technological operations in crop production // Agricultural machines and technologies. 2011.Vol. 5. №1. p. 11-14. 